Accepted refereed manuscript of:

Roxburgh M, McCallum J, McCrossan G \& Smith F (2018) A process of developing a national practice assessment document. Nurse Education in Practice, 33, pp. 17-20.

DOI: 10.1016/i.nepr.2018.08.011

(c) 2018, Elsevier. Licensed under the Creative Commons Attribution-NonCommercial-NoDerivatives

4.0 International http://creativecommons.org/licenses/by-nc-nd/4.0/

\title{
Title:
}

\section{A process of developing a national practice assessment document}

\section{Abstract}

This paper will share how one country within the United Kingdom (UK) collaborated on a national partnership approach in developing a consistent pre-registration undergraduate nursing practice learning assessment document. In 2011 the Scottish Heads of Academic Nursing and Allied Health Professionals (SHANAHP, now Council of Deans Scotland, CoDS) agreed to support the development of a Scottish national approach to practice learning assessment document (the "Scottish Ongoing Achievement Record"). Whilst no direct funding was received to support this work, each $\mathrm{HEI}$ agreed that this work would be recognised via the release of staff time to enable completion. Utilising a communities of practice approach to collaborative working, the national group incorporated the collective knowledge and experience of representatives from all Higher Education Institutes (HEls) in Scotland that provided undergraduate pre-registration nurse education. The work of the group will be described in four phases, Mapping of Influential Drivers; Guiding Principles and Good Practice; Document development; and Implementation. Appraisal of the advantages of this approach in light of international literature will be considered alongside challenges encountered during development and implementation.

\section{Highlights}

- National collaborative work

- National experience for all student nurses and nurse mentors

- Facilitation of recognition of prior learning (RPL) between HEls and FE colleges

\section{Key words}

Practice learning, undergraduate,collaboration, assessment.

\section{Introduction}

This paper will share how one country within the United Kingdom (UK) collaborated on a national approach to develop a consistent pre-registration undergraduate nursing practice learning assessment tool. The choices and challenges associated with this development will also be explored and the lessons learned will be revealed.

A central theme in UK government policy over the last 20 years concerning healthcare delivery is the need for partnership working (Department of Health (DOH) 2000; Scottish Government Health Department (SGHD) 2014, 2017). This originates from the recognition that professionals and services do not operate independently of each other. The requirement for partnership working is further evident in the number of government reports recommending this within the context of professional education for healthcare practitioners (SGHD 2010 2014, 2017). Furthermore, 
partnership working has been embraced by the UK's nursing and midwifery's regulatory body (Nursing \& Midwifery Council (NMC), 2008a, 2008b, 2010).

Partnership and collaborations in Scotland are considered so integral to undergraduate nurse preparation, that they have become enshrined in almost all our policy documents (Lauder et al. 2008), (SGHD 2010, 2014, 2017).

However following the publication of the NMC 2010 standards each higher education institution (HEI) / university in the UK and Scotland developed their own practice assessment document in order to meet the practice component for the standards. This meant that practice learning areas which support students from more than one $\mathrm{HEl}$ had different practice learning assessment tools to complete for each student, ultimately however to meet the same NMC standards and European Union requirements. This led to critique, particularly from nursing mentors surrounding the varied recording methods for practice learning assessment (Holland et al 2010).

A national study conducted within Scotland between 2006-2008 entitled Nursing and Midwifery in Scotland: Being Fit for Practice (Lauder et al. 2008) demonstrated many strengths and successes in the partnership arrangements in preparing our future nurses. However an area of major concern raised by both clinical practitioners, students and to a lesser extent HEl's was around the desire to streamline and simplify the practice assessment documents. This large scale study demonstrated that some mentors support students from up to 3 different HEl's, each with different practice learning documents, university requirements, and document layouts which posed them a real challenge and burden. A key request from mentors was to streamline, standardise and make the documents more mentor friendly (Lauder et al. 2008).

To date worldwide there have been publications regarding the development of practice learning assessment tools (Ulfvarson, \& Oxelmark, 2012, Skúladóttir \& Svavarsdóttir, 2016) and even city's or geographical areas developing a common practice learning assessment tool (Pan London: Baillie et al 2016 ; Pan Manchester) with only one other country wide approach (Wales, Cassidy 2012). The work of the Scottish working group incorporated all $12 \mathrm{HEls}$ that provide pre-registration nurse education in Scotland, and as such is the largest collaboration that we are aware of.

Our approach to working collaboratively was based on the premise of a Community of Practice (COP). COP has been widely defined as 'a model of situational learning, based on collaboration amongst peers, where individuals work to a common purpose, defined by knowledge rather than task' (Wenger 1998). Social interaction and collaboration are essential components of situated learning. The process of working together collaboratively and sharing knowledge can promote an enriched experience through the maintenance and exchange of knowledge with regard to the domain by dialogue. Chambers et al (2010) also emphasise the importance of identifying a shared vision with in the collaboration in order to jointly determine what needs to be accomplished and helps reduce future conflicts.

There are a number of advantages to taking a National approach. Lai (2011) informs us that true collaboration involves all the participants working together on the same issue, rather than in parallel. In addition it provides opportunity to share best 
practice, and the reduction of the potential for confusion amongst educators, students and mentors from different areas The practice assessment document, the group believed, would be transferable between $\mathrm{HEI}$ if a student decided to swap provider. This makes mapping to Recognised Prior Learning (RPL) simpler for HEl's and makes the RPL process easier to navigate. Moreover this approach is in line with NHS Education for Scotland (NES) (2011) guidance on practice assessment documentation which provides a common, but flexible and adaptable vision for a Scottish approach to assessment. Finally this also relates to the Review of Education provision in Scotland and the Chief Nurse's (SGHD 2014) stated commitment to produce a 'world class' education system.

\section{Aim}

All HEls within Scotland worked collaboratively together with the following aim:

- To develop and implement a national practice assessment document and associated supporting materials which map NMC pre-registration nursing education requirements, progression criteria and guidance.

\section{The Process}

Following approval from Council of Deans for Health Scotland, (CoDHS), the initial meeting of the national group was in December 2011. Membership was formulated through representation from each $\mathrm{HEI}$ in Scotland that provided pre registration nurse education. Twenty eight nurse educators and three Practice Education Facilitators made up the group and met approximately six weekly to progress this work over a three and a half year period. Representatives were all involved in practice learning and assessment of practice learning. The work of the group can be described in four phases (Table 1):

\section{Phases in the process \\ Mapping of Influential Drivers}

Phase 1 consisted of the group reviewing the professional context and drivers that shape pre registration nursing practice assessment in relation to progression and articulation. Although all members of the group had an extensive working knowledge of the NMC (2010) Standards for pre registration nurse education, Supporting Learning and Assessment in Practice Standards (2008) and National Health Service Education for Scotland (NES) (2011) Developing a National Approach to Practice Assessment Documentation for the Pre-Registration Nursing Programmes in Scotland, these were all reviewed by the group in light of the task at hand. Scottish Government Health Department drivers were reviewed and the group sought intelligence from other national working groups such as the Scottish Collaboration for Enhancement of Pre-Registration Nursing (SCEPRN) and the National Strategic group for Practice Learning (NSGPL) to inform the development of the Scottish document. Each individual HEl's regulations regarding assessment and progression were also shared and reviewed by the group.

The review of the professional context and drivers and other examples of shared assessment documentation resulted in the group setting criteria for components of the assessment model that the existing $\mathrm{HEI}$ practice could be mapped against. This thorough review enabled not only identification of 'good practice' (as determined by 
the group) but also areas of practice that would be strengthened by further enhancement.

\section{Guiding Principles and Good Practice}

All HEls shared their current practice learning assessment documents. The group used a cloud-based file sharing facility to ensure access for all of the group and to manage the 'large' documents. This facility also enabled a robust means of version control during the later phases of the work.

Emerging themes included, congruence, areas of differing practice, good practice and current approaches to practice learning documentation across Scotland were shared and debated by the group with monthly face to face meetings. Findings were mapped against the assessment model that had been developed during phase one and agreement was reached within the group of what the criteria for the assessment model template would be. This enabled all aspects of good practice from individual $\mathrm{HEls}$ to be identified and incorporated into the final assessment model.

\section{Document development}

Development of the Scottish documentation was a positive, solution and output focused process with open discussion and debate. Despite the potential challenge of debating twelve different approved practice assessment documentation, the discussions were collegiate and supportive thus enabling progression of the work.

This highlights as Roschelle \& Teasley (as cited in Dillenbourg et al., 1996, p. 2) that through our coordinated efforts and engagement we could solve a problem mutually.

The group reviewed and synthesised the range of practice assessment processes within each individual institution, considering key themes and anomalies. The group found areas that could be shared/duplicated and some aspects that geographical or health board specific. This key finding resulted in the structure of the Scottish document having sections that were applicable to all HEls and sections that were University specific (for example to explain the pre registration nursing programme structure within the specific $\mathrm{HEI}$ and the $\mathrm{HEl} /$ practice partner specific forms and information, for example raising a cause for concern guidance and documentation).

Following construction of the draft Scottish document, feedback was sought from students, mentors, practice partners, programme leaders, service users/carers, disability contacts within HEls and practice leads. A feedback template was developed to ensure consistency across all parties who were invited to participate.

The Scottish template document was presented to and endorsed by CoDHS in November 2014 for implementation into all pre-registration nursing programmes across Scotland from September 2015 with the ultimate agreed aim of all Scottish HEls using the document by the end of 2016.

\section{Implementation}

In the UK any changes must go to approval by the NMC. A pan Scotland approval event was explored with the NMC. However, with the wide range of re approval dates for existing programmes this proved problematic, therefore each individual $\mathrm{HEI}$ 
agreed to present the Scottish document at their next re approval event. The Scottish document and the work of the group has been consistently commended by the Nursing and Midwifery Council Reviewers.

\section{Discussion}

To date there is limited literature (Ulfvarson, \& Oxelmark, 2012, Skúladóttir \& Svavarsdóttir, 2016) on the development of practice assessment documents, never mind on a national level. This determination and success for partnership working is congruent with the Review of Education provision in Scotland (SGHD 2014) and the Chief Nurse's stated commitment to produce a 'world class' education system. The group are of the view that this will only be achieved through collaboration, where this is appropriate. The development of a Scottish position on practice education, assessment and progression is clearly one of these occasions when a collaborative solution was the best option and in line with the UK and Scottish government policy (DoH 2000, SGHD 2014,2017).

Setting the Direction (SGHD 2014, p13) clearly sets out within their strategic aim 4 that education providers should "collaborate across practice learning environments to achieve a consistent approach to placement assessment documentation for pre registration students". Thus the production of the Scottish document demonstrates achievement of this aim in undergraduate nursing and the stated aim of the group. Furthermore the Nursing 2030 vision (SGHD 2017) emphasises the importance of nurses being adequately prepared to meet the challenges incumbent in working collaboratively across health and social care professions. It is anticipated that the Scottish document will facilitate this process to enable our undergraduate nursing students to work across health and social care boundaries without the added complexity for mentors or supervisors of multiple assessments tools and methodology required by each $\mathrm{HEl}$. Thus the use of a single consistent practice document will enhance student support, interpretation and completion of assessment of practice.

The development of the Scottish document was not however without its challenges. To achieve the national group's aim of all HEls using of the Scottish OAR by 2016, the universities all required gaining approval to use the document from the regulatory body, the NMC. This was challenging to hold as a national event, and so each university went through the approval process individually. Thus there was not one launch event, but individual universities moving to its use at different times.

The work of the group and the resultant Scottish document has been presented to both national and international audiences. Presentation of the work of the Sottish document group at the Nurse Education Today/Nurse Education in Practice (NETNEP) conference in Brisbane in March 2016, elicited positive acclaim from an international audience and generated interest from the NMC. Therefore, if there is an appetite for a standardised national approach to practice assessment, the work and key process stages of the Scottish document group would be well placed to inform the development of a national practice learning assessment document.

The success of this collaborative approach has now been replicated in developing a Scottish Memorandum of Understanding for all HEls and service providers with regards to placements. Furthermore a national approach to managing concerns 
raised in practice is underway. Future plans are also under discussion to develop a national approach to Fitness to Practise. A further success can also be noted in that a number of Further Education (FE) Colleges who provide Access to nursing courses are about to embark on implementing the Scottish document with their students. Again this will provide consistency when these students access their clinical placements and will also afford the HEl they apply to post finishing FE to recognise their prior learning.

Now that the Scottish document has been used in undergraduate nursing programmes in Scotland for 2 years the next steps are to formally evaluate it. There has been anecdotal feedback from nursing mentors, students and practice education facilitators that it is easy to navigate, less onerous than what went before, well organised and easy to understand and very user friendly as it is clear what is expected in each section. Evaluation will also assist the group when developing the practice assessment document for the new NMC pre-registration standards which will be published in the spring of 2018 by knowing what works well.

\section{Conclusion}

The collegiate working of all the HEls in Scotland who provide undergraduate nursing programmes has proved to be an extremely successful collaboration with the achievement of the aim. The development of the Scottish document has been received well from students, nurse mentors, lecturers and the NMC. It has also helped to meet some of the national objectives around practice learning and collaboration with it facilitating recognition of prior learning for practice within the universities. This innovative partnership working would be informative to any HEls internationally where there is a national professional body and more than one institution providing undergraduate pre-registration nursing education.

\section{References}

Baillie, L., Fish, J., Barclay, J., Case, D., Crussell, J., O'Brien, M., Icheku, V., Humphries, P., Thompson, S., Mitchell, J. (2016) Assessing nursing students in practice: a mixed method evaluation of a unified assessment document. Available at https://www.heacademy.ac.uk/system/files/downloads/baillie-

assessing nursing students.pdf (Accessed 6/01/17)

Cassidy, S. (2012) Important changes to pre-registration nurse education. Llais available at https://www.ldw.org.uk/media/236909/llais issue 104-eng-6.pdf (Accessed 5/1/2017)

Chambers $\mathrm{R}$ et al (2008). Regional collaborative practice in psychiatric rehabilitation and recovery: a best practice model. Journal of Social Work in Disability and Rehabilitation, 7(3-4), 187-231.

Department of Health (2000) The NHS Plan: a plan for investment, a plan for reform.DoH, London 
Dillenbourg P., Bake, M., Blaye A., \& O'Malley, C. (1996). The evolution of research on collaborative learning. In E. Spada \& P. Reiman (Eds.), Learning in humans and machine: Towards an interdisciplinary learning science (pp. 189-211). Oxford: Elsevier.

Holland K., Roxburgh M., Johnson M., Topping K., Watson R., Lauder W., Porter M (2010) Fitness for practice in nursing and midwifery education in Sctland, United Kingdom. Journal of Clinical Nursing, 19, 461-469

Lai E R (2011) Collaboration: A Literature Review. Research Report.

Available at http://www.pearsonassessments.com/research. Accessed 16/02/2018

Lauder W., Roxburgh M., Holland, K., Watson, R., Johnson, M. (2008) Nursing and Midwifery in Scotland: Being Fit for Practice. The Report of the Evaluation of Fitness For Practice Pre-Registration Nursingand Midwifery Curricula Project Final Report

National Health Service Education for Scotland (NES) (2011) Developing a National Approach to Practice Assessment Documentation for the Pre-Registration Nursing Programmes in Scotland. NES, Edinburgh

Nursing and Midwifery Council (2006) Consultations on Proposals arising from a Review of Fitness for Purpose at the Point of Registration. NMC Circular 31/2005. NMC, London.

Nursing and Midwifery Council (2008a) Standards to support learning and assessment in practice. NMC, London.

Nursing and Midwifery Council (2008b) Code of Conduct; Standards of conduct, performance and ethics for nurses and midwives. NMC, London.

Nursing and Midwifery Council (2010) Standards for pre-registration Nursing Education. NMC, London.

Scottish Government Health Department (2017) Nursing 2030 vision. Scottish Government; Edinburgh

Scottish Government Health Department (2014) Setting the direction for nursing and midwifery education in Scotland. Scottish Government; Edinburgh

Scottish Government Health Department (2010) The Healthcare Quality Strategy for NHSScotland. Scottish Government; Edinburgh

Skúladóttir H.\& Svavarsdóttir, M.H (2016) Development and validation of a Clinical Assessment Tool for Nursing Education (CAT-NE). Nurse Education in Practice. 20;31-38 
Ulfvarson, J \& Oxelmark, L (2012) Developing an assessment tool for intended learning outcomes in clinical practice for nursing students. Nurse Education Today. 32(6): 703-708

Wenger, E (1998) Communities of Practice: Learning, Meaning and Identity. Cambridge University Press, NY. 